have been confirmed ${ }^{7}$ and others are still speculation. ${ }^{8}$ Reports of an association between vaccines and adverse outcomes get much public attention, and it often becomes difficult to determine whether the public is getting the appropriate information for an informed decision. Recently the possible association of measles vaccination with ileal lymphoid nodular hyperplasia and developmental disorders was reported..$^{9}$ In the flurry of correspondence criticising this paper, several wrote of the potential harm to public health vaccination programmes because of individuals becoming aware of this possible but unproved association. It was implied that individuals might now perceive the risk from measles to be outweighed by the risks of adverse effects from the vaccine. The recurring challenge for public health authorities is to find the best way to communicate with the public, so that they truly are informed on the relative risks and benefits of a vaccine programme.

Can the public and individual interests be served simultaneously? This can be achieved when a vaccine programme is started. At that point the disease incidence is high and the relative rate of vaccine adverse effects low. However as the vaccine programme becomes more successful in eradicating the disease, public and individual interests may diverge unless the vaccine has no adverse effects or the programme is so successful that the disease is eliminated and the vaccine programme can be discontinued. This was achieved for smallpox. However, in a voluntary programme it may always remain difficult to achieve a high enough uptake to achieve elimination for congenital rubella syndrome because some individuals will perceive the risks of vaccination as outweighing the benefits and decline vaccination. But one lesson from the Greek experience is not to introduce vaccination programmes half heartedly-either in terms of the evidence underlying the policy or in systematically promoting it.

Susan King associate professor of paediatrics

Division of Infectious Diseases, Hospital for Sick Children, Toronto, Ontario, Canada M5G 1X8

1 Panagiotopoulos T, Antoniadou I, Valassi-Adam E. Increase in congenital rubella occurrence after immunization in Greece: retrospective survey and systematic review. BMJ 1999:319:1462-7.

2 Bart KJ, Orenstein WA, Aeblud DR, Hinman AR. Universal immunisation to prevent rubella. Rev Infect Dis 1985;7(suppl):177-84.

3 Miller E, Waight P, Gay N, Ramsay M, Vurdien J, Morgan-Capner P, et al. The epidemiology of rubella in England and Wales before and after the 1994 measles and rubella vaccination campaign: fourth joint report from the PHLS and the National Congenital Rubella Surveillance Programme. CDR 1997;7:R26-32.

4 Kadoya R, Uleda K, Miyazaki C, Hidaka Y, Tokugawa K. Incidence of congenital rubella syndrome and influence of the rubella vaccination program in Japan 1981-1989. Am J Epidemiol 1998;148:263-8.

5 Hinman AR, Hersh BS, de Quadros CA. Rational use of rubella vaccine for prevention of congenital rubella in the Americas. Pan Am J Pub Health 1998;4:156-60.

6 Gangarosa EJ, Galazka AM, Wolfe CR, Phillips LM, Gangarosa RE, Miller $\mathrm{E}$, et al. Impact of anti-vaccine movements on pertussis control: the untold story Lancet 1998:351:356-61.

7 Miller E, Goldacre M, Pugh S, Colville A, Farrington P, Flower A, et al. Risk of aseptic meningitis after measles, mumps, and rubella vaccine in UK children. Lancet 1993;341:979-82.

8 Howson CP, Katz M, Johnston RB, Fineberg HV. Chronic arthritis after rubella vaccination. Clin Infect Dis 1992;15:307-12.

9 Wakefield AJ, Murch SH, Anthony A, Linnell J, Casson DM, Malik M, et al. Ileal-lymphoid-nodular hyperplasia, non-specific colitis, and pervasive developmental disorder in children. Lancet 1998;351:637-41.

\title{
Learning from the NHS
}

\section{NHS continues to be an important test bed for reform in health care}

An advertisement for the conference "Learning from the NHS" appears on outside back cover (clinical research classified), facing p 1500 (general practice), and facing p 1447 (other editions).

Contact Jane Lewis (jlewis@bma.org.uk) for more details.
$\mathrm{T}$ he British National Health Service has been a great inspiration for other countries during the past 50 years. A central theme has been the role that the state can play in securing health care for its population. What can other countries learn from the latest reforms in the NHS and the new role of the government in health care?

Governments have become central to health policy, engaging in both the financing and the provision of a wide range of care. Most countries in the Organisation for Economic Cooperation and Development, for example, have achieved universal access to health care through a mix of public and private providers and sources of finance. ${ }^{1}$ Proponents of public sector involvement in health care have rooted their arguments in both philosophical and technical grounds. In most societies care for the sick and disabled is considered an expression of humanitarian aspirations. But economic theory also provides ample justification for such an engagement to secure efficiency ${ }^{2}$ and equity. ${ }^{3}$ The past 100 years is rich with examples of how market forces have failed in health care.

In the past 50 years, prompted by the problems of market failure, many low and middle income countries established state funded healthcare systems with services provided by vertically integrated public bureaucracies. During the 1980s and 1990s the pendulum swung in the other direction. In the Reagan and Thatcher era the world witnessed a growing willingness to experiment with market approaches in health, education, and social protection. ${ }^{4}$ This was true even in countries which were bastions of the welfare state, such as the United Kingdom, New Zealand, and Australia.

As with the original rise in state involvement in health care, the recent enthusiasm for private solutions has both ideological and technical roots. Liberalisation in many former socialist states and the economic shocks in East Asia and Latin America certainly contributed to a global sense of urgency to reform inefficient bureaucracies and sharpen lines of accountability. ${ }^{5}$ But it would be too easy to blame ideology and economic crises alone for exposing public services to competitive market forces and increasing private sector participation. In reality, the welfare state approach has not always met the health needs of populations.. ${ }^{6}$ Although state involvement is clearly needed, it has been dogged with the failure of the public sector to provide the services well. ${ }^{7}$

Two related themes dominate. The familiar one is, what can governments do to make the public sector more responsive to a rapidly changing environment? The newer one is not whether the market should 
substitute where the public sector fails, but whether there can be a better match between the roles of state and private sectors, using their respective strengths to do better than either could alone.

In most countries such a "third way" means rebalancing an already complex mix of public and private roles in the health sector. The prime mover in this must be government. The possible actions governments can take to improve efficiency, equity, responsiveness, and quality in public sector health care are extensive-and the latest reforms in the NHS illustrate this.

Major departures from the past include: replacing fundholding practices with primary care groups; introducing clinical governance to improve the clinical quality of care; and giving the public access to 24 hour advice on health and illness via the telephone or on line. ${ }^{8}$ Of the four main objectives, responsiveness and quality seem to have a higher priority than equity and efficiency.

The policies combine a dual approach to improving performance. On the one hand there is strong central direction: clear national standards (for example, through the National Institute of Clinical Excellence $^{8}$ ); more independent scrutiny of the quality of clinical care (for example, through the Commission for Health Improvement ${ }^{8}$ ); and the publication of national performance indicators. ${ }^{9}$ On the other hand there is an encouragement of "horizontal" networks NHS organisations working in partnerships with others towards solving problems, not reinforcing old barriers (for example, health action zones ${ }^{10}$ and primary care groups $\left.{ }^{8}\right)$. This combination of strong vertical direction and vibrant horizontal networks is an emerging feature in successful European companies. ${ }^{11}$ In the NHS achieving the "strong vertical" is all too easy; the "vibrant horizontal" needs a lot more thought.

The third way between public and private sector is less clear. Public-private partnerships in capital projects (the private finance initiative) need reforming but will remain. New methods of regulating private sector providers are out for consultation. ${ }^{12}$ Beyond that the path is as yet hard to make out. But the bald statement "what counts is what works" suggests the UK government is at least open to ideas.

These two themes-reforming the public sector in health care and achieving a better balance between public and private sectors-are issues that will be explored in the forthcoming $B M J$ conference "Learning from the NHS."

Jennifer Dixon policy adviser

Chief Executive's Private Office, NHS Executive, London SW1A 2NS

Alex Preker senior health economist

Human Development Department, World Bank, Washington, DC 20433, US

1 Preker AS. The introduction of universality in health care. London: IIHS 1989.

2 Bator F. The anatomy of market failure. In: Estrin S, Marin A, eds. Essential readings in economics. New York: St Martin's Press, 1995:129-58.

3 Arrow KW. Uncertainty and the welfare economics of medical care American Economics Review 1963;53:940-73.

4 Young P. Privatization around the globe: lessons from the Reagan administration. Houston: National Center for Policy Analysis, 1986.

5 World Bank. Investing in people and growth. In: World development report: from plan to market. New York: Oxford University Press, 1996;123-32.

6 World Health Organisation. European health care reforms: analysis of current strategies. Copenhagen: WHO Regional Office for Europe, 1996.

7 Preker AS, Feachem RGA. Market mechanisms and the health sector in central and eastern Europe. Washington, DC: World Bank, 1996.

8 Department of Health. The new NHS. London: Stationery Office, 1997 (http://www.open.gov.uk/doh).

9 Department of Health. Performance assessment framework. London: Department of Health, 1999

10 Department of Health. Health action zones. London: Department of Health, 1997 (EL(97)65).

11 Whittington R, Pettigrew A, Peck S, Fenton E, Conyon M. Change and complementarities in the new competitive landscape: a European pane study, 1992-1996. Organization Science, in press.

12 Department of Health. Regulating private and voluntary healthcare: a consultation document. London: Stationery Office, 1999.

\section{Medicine must change to serve an ageing society}

\section{Eradicate age discrimination and increase resources}

$\mathrm{D}$ octors and those responsible for commissioning and shaping health services have failed to acknowledge the rapid ageing of most societies. This worldwide phenomena is unprecedented, leaving us ignorant, fearful, and reluctant to tackle it face on. A conference in London last month examined how medicine and its institutions must change to serve a growing older population while still meeting the needs of younger people. Two issues dominated: age discrimination and resources.

Currently $20 \%$ of the population of the United Kingdom is over $60-12$ million people. By 2031 this proportion will be nearly a third-18.6 million people. ${ }^{1}$ Most will lead healthy and rewarding lives, but the numbers of people needing acute and long term care will inevitably increase. Rates of cardiovascular disease, dementia, and osteoarthritis among elderly people in the next century will be greatly determined by success or failure now in preventing such disease.
Health care is ill suited to perform well in a world with many more elderly people because it is ageist. Older people face arbitrary discrimination in their encounters with health professionals, ${ }^{2}$ and this probably reflects a wider ageism within society. Older people are excluded from research and many beneficial interventions, some of which would be lifesaving, and are insensitively managed. ${ }^{3}$

Recent changes in acute medical services in Britain have created an environment where ageism flourishes. More and more older people are admitted to fewer and fewer beds for shorter and shorter stays. Nearly a third of beds for acute cases are now occupied by people over 75, and the throughput per bed has more than doubled over the past 10 years in the geriatric sector. ${ }^{4}$ General practitioners are also under pressure, caring for increasing numbers of disabled elderly people in nursing homes.

The health needs of most older people are the same as for everyone else, but the oldest old, and those 